\title{
Coronary CT Angiography untuk deteksi plak rapuh, sebagai bagian dari usaha pencegahan Sindrom Koroner Akut
}

\author{
Sonny Hilal Wicaksono
}

\section{Pendahuluan}

Tindakan Primary Percutaneous Coronary Intervention (PPCI) untuk pasien sindrom koroner akut (SKA) dengan ST elevasi (STEMI=ST elevation myocardial infarction) telah berjasa banyak dalam menurunkan mortalitas. Namun kerusakan jaringan miokard pasca $P P C I$ tetap terjadi, akibat iskemia yang telah berlangsung sebelum reperfusi berhasil, atau kerusakan jaringan miokard akibat cedera reperfusi. Hal tersebut menimbulkan konsekuensi morbiditas akibat SKA berupa gagal jantung. Sehingga dikhawatirkan bila SKA tidak dicegah, di masa yang akan datang akan timbul epidemi gagal jantung. Oleh sebab itu strategi pencegahan terjadinya SKA perlu menjadi pengetahuan dasar bagi seluruh dokter spesialis jantung dan pembuluh darah (SpJP) agar epidemi gagal jantung dapat dicegah.

Strategi pencegahan SKA tetap memegang 5 prinsip:

1. Health Promotion

2. Primary Prevention

3. Early Detection and Prompt Treatment

4. Secondary Prevention

5. Rehabilitation

\section{Alamat Korespondensi}

dr. Sonny H Wicaksono, SpJP. Departemen Kardiologi dan Kedokteran Vaskular, FKUI dan RS Puri Indah, Jakarta. email: dr.sony. hw@gmail.com
Poin pertama dan kedua dilakukan langsung ke tengah masyarakat di luar klinik atau rumah sakit, mulai dari poin ke-tiga, yaitu deteksi dini, dilakukan dalam praktek klinik.

\section{Deteksi dini pasien risiko tinggi SKA}

Deteksi dini pasien dengan risiko tinggi SKA memerlukan pemahaman tentang penyebab SKA. SKA disebabkan oleh rupturnya plak aterosklerosis. Plak aterosklerosis yang ruptur adalah plak yang rapuh.* Karakter plak rapuh yang ruptur telah dipelajari secara histologis, hasil biopsi dari pasien yang meninggal akibat STEMI, yaitu ditemukan plak kaya lemak dengan inti nekrotik yang luas dengan atap plak yang berupa jaringan ikat fibrosa tipis yang rapuh(gambar 1). $(1,2)$

Temuan histologis ini kemudian oleh MaurovichHorvat dicocokkan dengan hasil pencitraan Coronay Computed Tomography Angiography (CCTA). Dari hasil penelitian tersebut disimpulkan bahwa plak rapuh dapat dilihat dari hasil pencitraan CCTA berupa gambaran khas yang tampak seperti cincin yang diberi nama Napkin-Ring Sign(NRS)(gambar 2). Napkin-Ring Sign didefinisikan sebagai temuan CCTA berupa plak dengan gambaran atenuasi rendah di tengah plak yang berdekatan dengan lumen arteri koroner yang dikelilingi oleh area dengan atenuasi yang lebih tinggi.(3) 

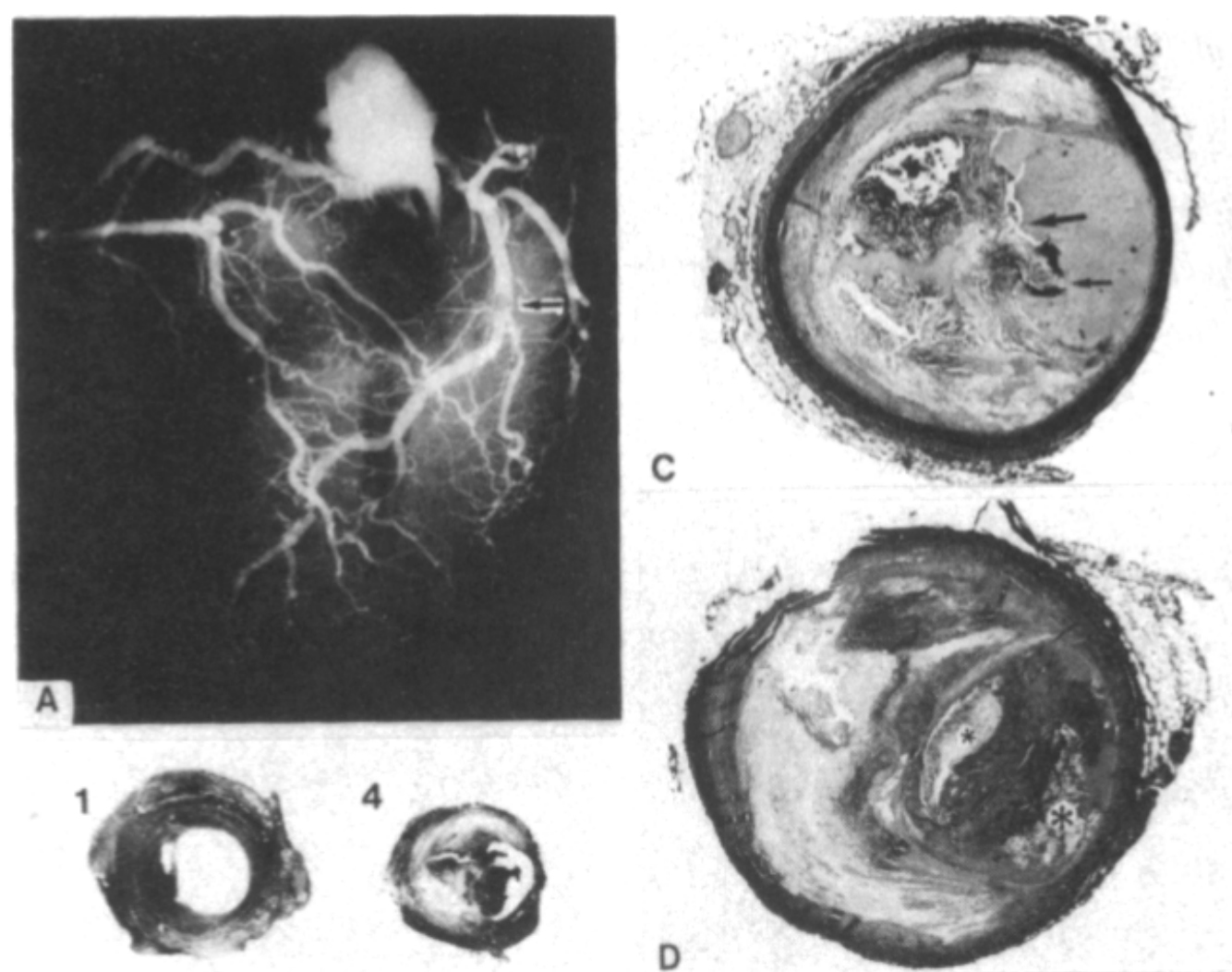

2
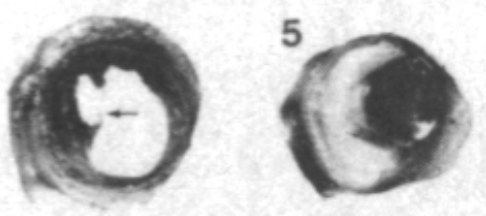

B

3

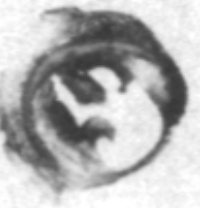

6

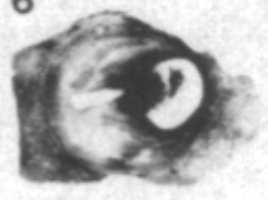

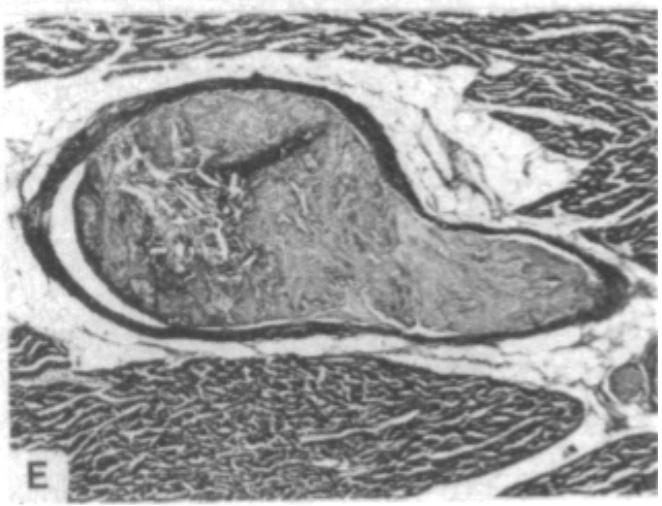

Gambar 1. Gambar A adalah hasil angiografi koroner invasif post mortem pasien meninggal diduga akibat serangan jantung yang fatal, gambar B, C, D dan E menggambarkan temuan histologis lesi arteri koroner yang mengakibatkan serangan jantung fatal akibat ruptur plak dan oklusi trombus. (dikutip dari (1))

Temuan Napkin-Ring Sign dari hasil CCTA telah dibuktikan merupakan representatif plak rapuh pada arteri koroner. Namun, dalam prinsip kedokeran berbasis bukti, untuk mengaitkan dengan SKA, perlu dibuktikan dengan penelitian yang metodologinya sesuai. Otsuka dkk mempublikasikan sebuah studi di JACC: Cardiovascular Imaging tahun 2013 yang lalu, tentang peran (NRS) pada CCTA untuk prediksi kejadian SKA, studi tersebut adalah yang pertama kali mendemonstrasikan hubungan temuan NRS pada CCTA dengan kejadian SKA. Hasil studi tersebut menyimpulkan bahwa deteksi $N R S$ dapat membantu mengidentifikasi pasien berisiko tinggi mengalami SKA di masa yang akan datang. Gambar 3 menampilkan contoh kasus SKA yang sebelumnya pernah CCTA dan ditemukan NRS.(4) 


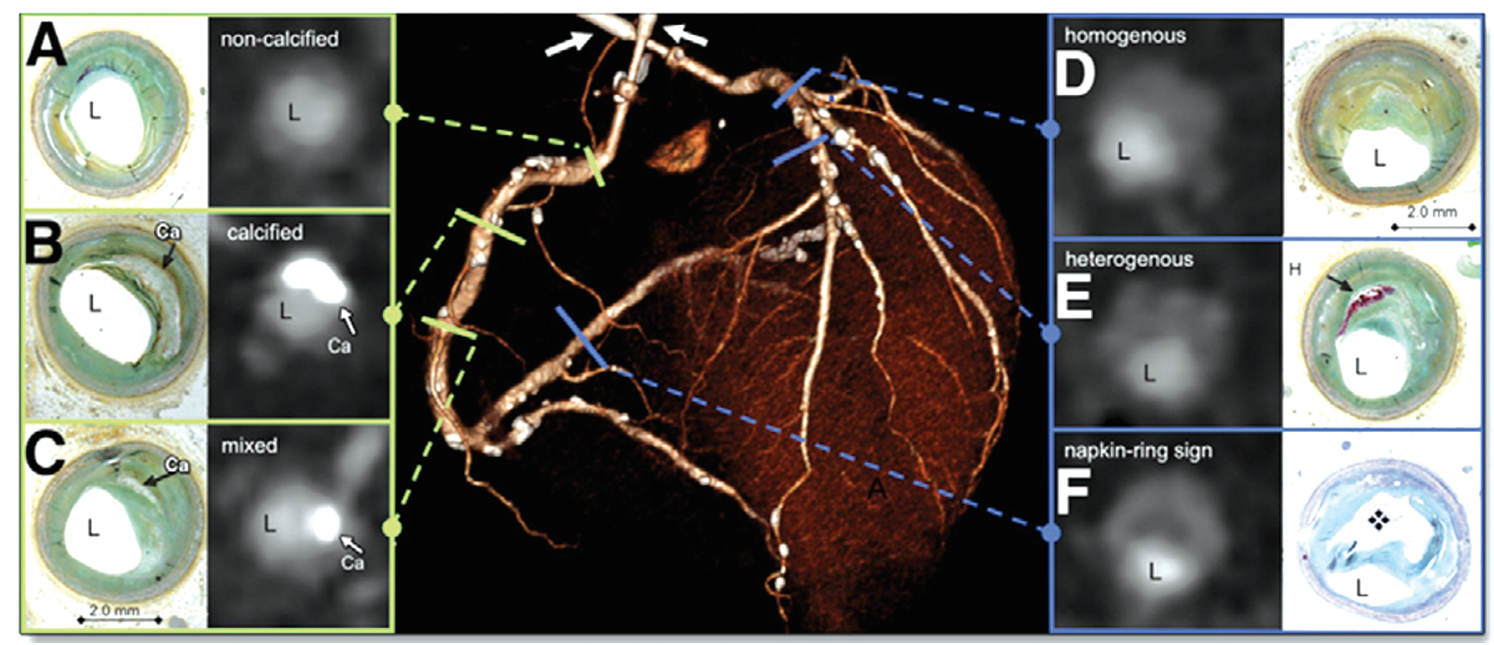

Gambar 2. Gambar A, B, C, D, E dan F adalah perbandingan temuan histologis dengan temuan CCTA. $\mathrm{L}$ adalah lumen arteri koroner. Gambar $\mathrm{F}$ yang diberi nama napkin-ring sign, adalah gambaran lesi plak aterosklerosis yang paling rapuh.(dikutip dari (3))
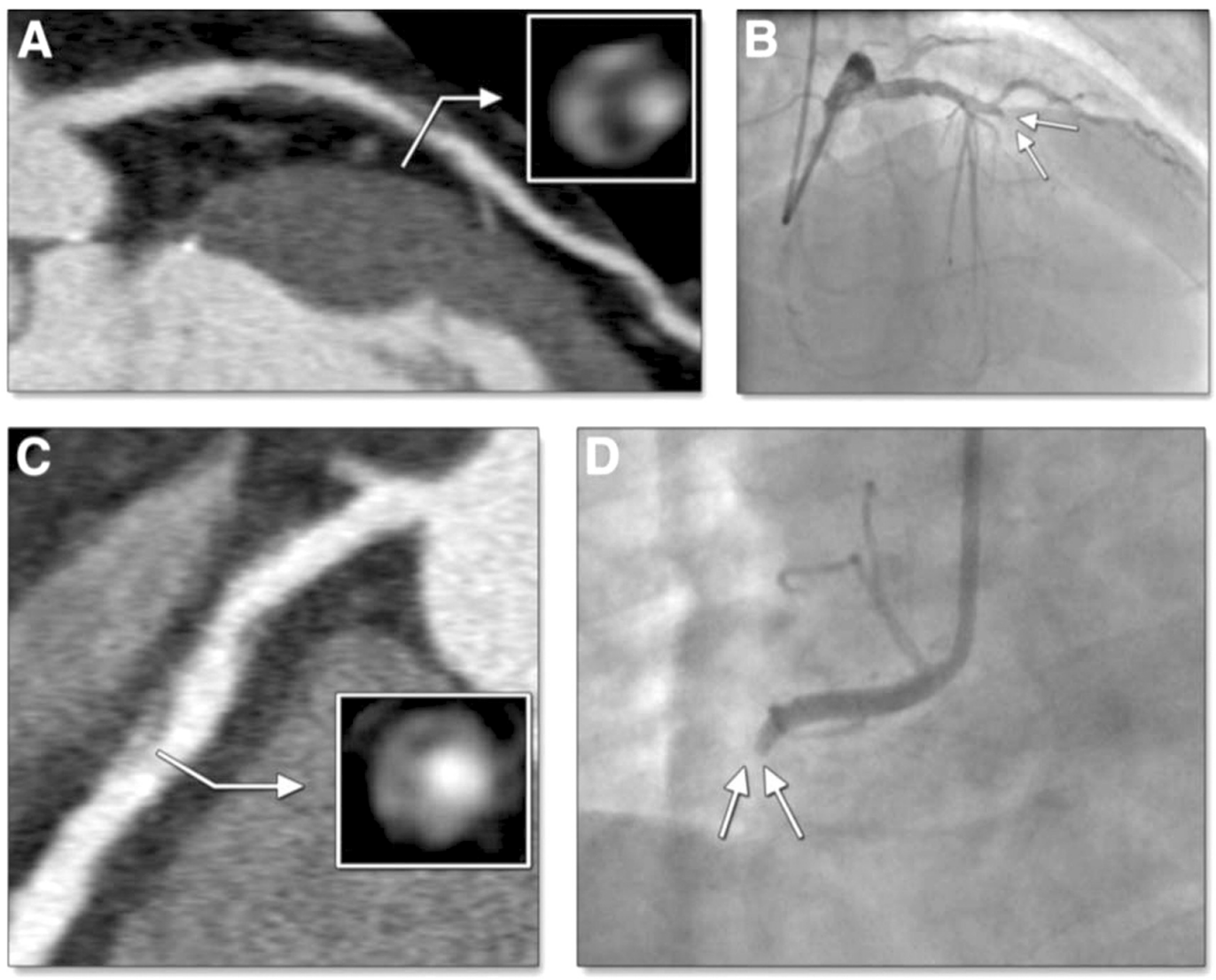

Gambar 3. Dua contoh kasus SKA pada pasien yang pernah dilakukan CCTA dari studi oleh Otsuka dkk, kasus pertama saat CCTA (A) dan 10 bulan kemudian saat SKA pada temuan angiografi koroner invasif (B), kasus kedua saat CCTA (C) dan 1 tahun kemudian saat SKA pada temuan angiografi koroner invasif (D).(dikutip dari (4)) 


\section{CCTA dalam the First SHAPE guidelines}

Evidence yang cukup kuat telah membuktikan bahwa $N R S$ pada CCTA mengidentifikasi pasien dengan risiko tinggi kejadian SKA di masa yang akan datang. Selanjutnya, apakah berarti semua pasien yang datang ke praktek dokter SpJP langsung dianjurkan CCTA untuk deteksi dini plak rapuh? Karakter pasien seperti apa yang dapat dikirim untuk menjalani CCTA dalam rangka deteksi dini plak rapuh?

Untuk menjawab pertanyaan tersebut, terdapat dua panduan utama yang perlu disimak, pertama the First SHAPE (Screening for Heart Attack Prevention and Eradication) guidelines tahun 2006 oleh Naghavi dkk, yang kedua 2013 ESC guidelines untuk penyakit arteri koroner (PAK) stabil oleh The Task Force on the management of stable coronary artery disease of the European Society of Cardiology.

Naghavi dkk bersama Society of Heart Attack Prevention and Eradication (SHAPE) Task Force mempublikasikan the First SHAPE (Screening for Heart Attack Prevention and Eradication) guidelines pada tahun 2006 yang membuat flow chart berdasarkan 2 teknik pencitraan noninvasif: coronary artery calcium scoring (CACS) menggunakan CT dan carotid intima media thickness (IMT) dan plak menggunakan ultrasonografi $B$-mode untuk deteksi dini aterosklerosis pada pasien asimtomatik(Gambar 3).(5) Guidelines tersebut sampai saat ini belum direvisi karena telah terbukti memperbaiki strategi penatalaksanaan pasien yang menghasilkan keluaran yang superior.

Berdasarkan guideline dari SHAPE, maka layak

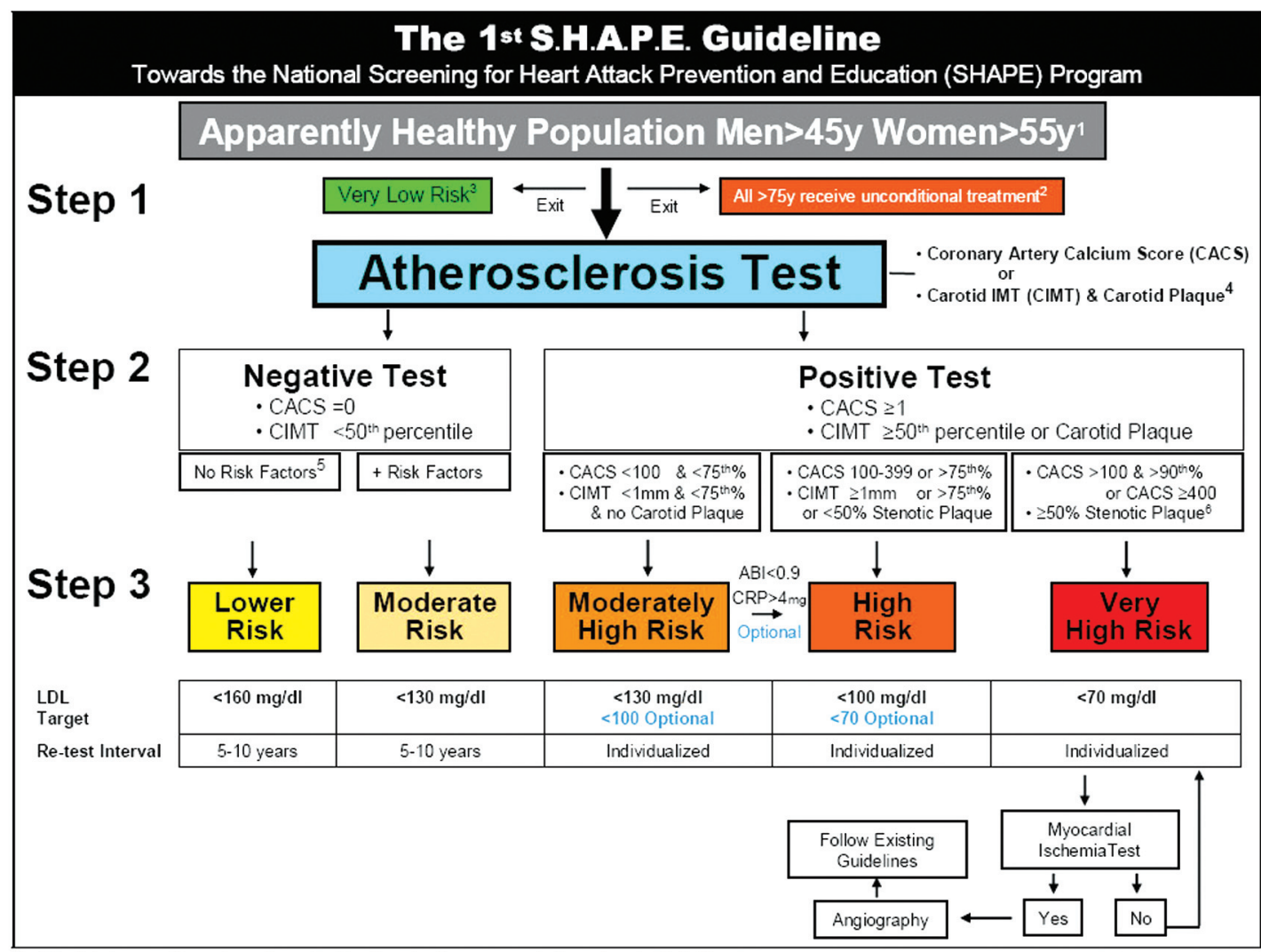

1: No history of angina, heart attack, stroke, or peripheral arterial disease.

2: Population over age $75 \mathrm{y}$ is considered high risk and must receive therapy without testing for atherosclerosis.

3: Must not have any of the following: Chol $>200 \mathrm{mg} / \mathrm{dl}$, blood pressure $>120 / 80 \mathrm{mmHg}$, diabetes, smoking, family history, metabolic syndrome.

4: Pending the development of standard practice guidelines.

5: High cholesterol, high blood pressure, diabetes, smoking, family history, metabolic syndrome.

6: For stroke prevention, follow existing guidelines.

Gambar 3. Flow chart dari the first SHAPE guidelines yang menganjurkan CT Coronary Artery Calcium Scoring (CACS) untuk deteksi dini PAK pada pasien yang tampak sehat.(dikutip dari Naghavi dkk (5)) 
bagi kardiolog untuk menganjurkan pemeriksaan CT calcium skor untuk skrining PAK pada pasien yang tampak sehat pada laki-laki usia di atas 45 tahun dan pada perempuan di atas usia 55 tahun.

Kelemahan teknik skoring kalsium arteri koroner adalah populasi pasien dengan plak rapuh yang tidak mengandung kalsium tidak tersaring dalam skrining menggunakan the $1^{s t}$ SHAPE guidelines yang terbit tahun 2006 yang lalu.

\section{CCTA dalam 2013 ESC guidelines untuk PAK stabil}

Panduan berikutnya dari 2013 ESC guidelines untuk PAK. Panduan diagnosis PAK dalam 2013 ESC

Tabel 1. Pembagian Pre-Test Probability (PTP) PAK pasien (dalam \%) berdasarkan usia, jenis kelamin dan keluhan. dikutip dari ${ }^{6}$

\begin{tabular}{|l|l|l|l|l|l|l|}
\hline & \multicolumn{2}{|l|}{ Typical angina } & \multicolumn{2}{l|}{ Atypical angina } & \multicolumn{2}{l|}{ Non-anginal pain } \\
\hline Age & Men & Women & Men & Women & Men & Women \\
\hline $30-39$ & 59 & 28 & 29 & 10 & 18 & 5 \\
\hline $40-49$ & 69 & 37 & 38 & 14 & 25 & 8 \\
\hline $50-59$ & 77 & 47 & 49 & 20 & 34 & 12 \\
\hline $60-69$ & 84 & 58 & 59 & 28 & 44 & 17 \\
\hline $70-79$ & 89 & 68 & 69 & 37 & 54 & 24 \\
\hline$>80$ & 93 & 76 & 78 & 47 & 65 & 32 \\
\hline
\end{tabular}

guidelines untuk PAK tidak untuk pasien tanpa keluhan, melainkan untuk pasien dengan keluhan. Namun keluhannya tidak harus angina yang khas, angina yang tidak khas, bahkan keluhan bukan angina pun mendapat tempat. Dalam guidelines tersebut, sebelum diperiksa lebih lanjut, pasien dibagi Pre-Test Probability (PTP) untuk PAK berdasarkan golongan usia dan jenis kelamin ditambah faktor keluhan angina. (Tabel 1)(6)

Berdasarkan perhitungan PTP dari tabel di atas, pasien kemudian dibagi menjadi tiga golongan, yaitu PTP $<15 \%$, PTP $15-85 \%$ dan PTP $>85 \%$. Pasien dengan PTP $15-85 \%$ dianjurkan untuk menjalani uji noninvasif untuk penegakan diagnosis PAK.(gambar 4)

Penegakan diagnosis PAK yang dianjurkan dalam 2013 ESC guidelines dapat melalui dua teknik noninvasif sebagai berikut:(6)

1. Uji stress untuk menilai iskemia

2. CCTA untuk menilai anatomi koroner

CCTA dapat memvisualisasi arteri koroner dan lumennya. CCTA unggul dalam menyingkirkan keberadaan PAK. Sensitiviti CCTA (64 slice) tertinggi dalam sebuah meta-analisis mencapai 98-99\%, dengan Negative Predictive Value tertinggi 99-100\%. Sedikit kekurangan CCTA adalah dalam menentukan stenosis dengan spesifisiti 82-89\% dan Positive Predictive Value 91-93\%.(7)

Kemampuan deteksi stenosis arteri koroner menurun dengan meningkatnya skor kalsium, dan

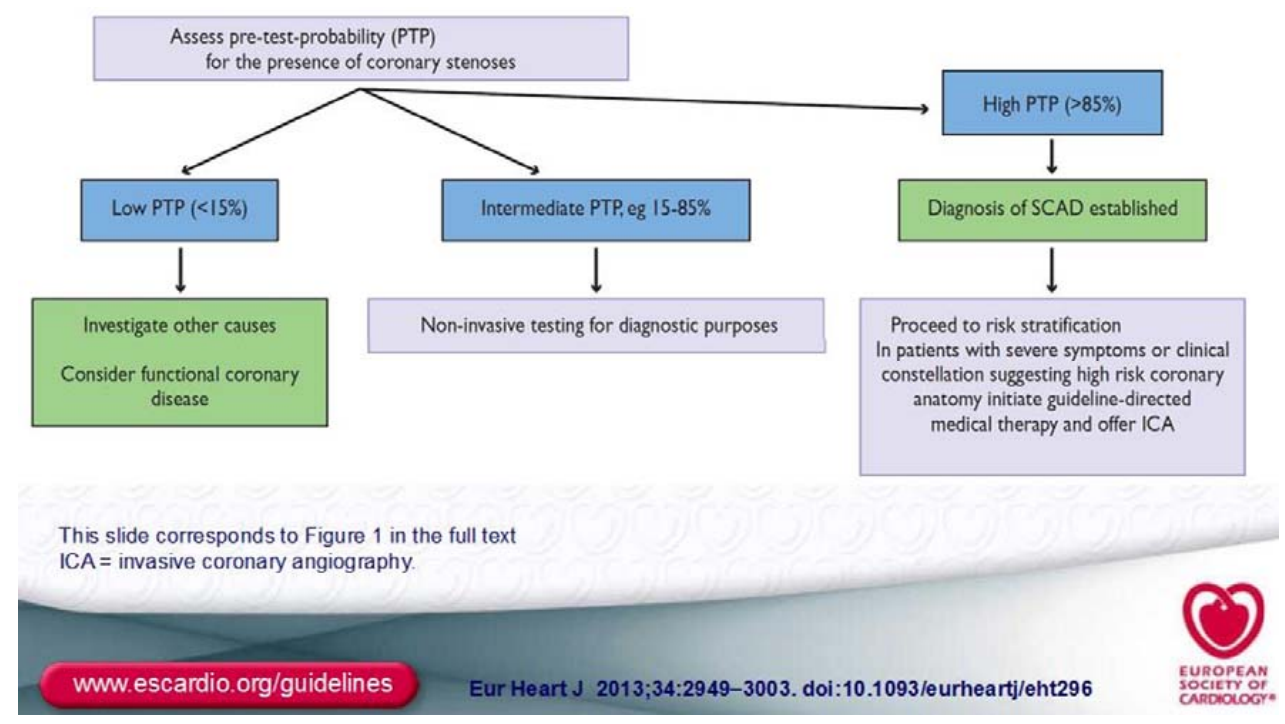

Gambar 4. Setelah menilai PTP, pasien dengan PTP 15-85\% dianjurkan menjalani uji noninvasif untuk tujuan diagnostik PAK.(dikutip dari (6)) 
prevalensi stenosis tinggi pada pasien simtomatik dengan Agatston skor $>400$, maka bila saat skoring kalsium ditemukan Agatston skor $>400$, dapat dimaklumi untuk tidak melanjutkan ke CCTA bila ingin menilai derajat stenosis.

Sehingga ESC guidelines menganjurkan CCTA terutama untuk pasien dengan PTP 15-50\%. Sementara yang lebih tinggi kemungkinan PAK, lebih dianjurkan untuk teknik pencitraan noninvasif dengan uji stress untuk menilai iskemia. ESC tidak merekomendasikan CCTA untuk skrining pada pasien asimtomatik yang tidak memiliki kecurigaan klinis ke arah PAK. ${ }^{6}$

Kualitas hasil CCTA sangat ditentukan oleh beberapa persyaratan yang harus dipenuhi yaitu:(8)

1. Alat $C T$ minimal 64 slice

2. Mampu menahan nafas

3. Tidak ada obesitas yang parah

4. Skor kalsium Agatston $<400$

5. Irama EKG sinus ritme

6. Laju nadi $<65 \mathrm{x} /$ menit atau kurang. (Bila perlu gunakan obat penurun laju nadi).

\section{Kesimpulan}

Memadukan kedua guidelines dalam penggunaan CCTA, usaha mencegah SKA dapat dilakukan dengan dengan mengaplikasikan flow chart dari the first SHAPE guidelines, yaitu langsung mendeteksi aterosklerosis sebagai langkah awal, namun tidak hanya melalui $C A C S$, karena perlu dilihat keberadaan plak rapuh yang hanya dapat dilihat secara noninvasif melalui pemeriksaan CCTA berupa temuan NRS, layak dianjurkan pada pasien yang dicurigai PAK berdasarkan tabel PTP dari 2013 ESC guidelines untuk PAK stabil. Berdasarkan kedua guidelines tersebut, dapat dikatakan bahwa CCTA dianjurkan bukan untuk mendiagnosis iskemia menggantikan teknik pencitraan noninvasif stress, namun untuk mendiagnosis aterosklerosis dan plak rapuh yang juga punya nilai prediktif bermakna untuk kejadian SKA.

\section{Daftar Pustaka}

1. Falk E. Plaque rupture with severe pre-existing stenosis precipitating coronary thrombosis. Characteristics of coronary atherosclerotic plaques underlying fatal occlusive thrombi. British heart journal. 1983 Aug;50(2):127-34. PubMed PMID: 6882602. Pubmed Central PMCID: 481384.

2. Virmani R, Burke AP, Farb A, Kolodgie FD. Pathology of the vulnerable plaque. Journal of the American College of Cardiology. 2006 Apr 18;47(8 Suppl):C13-8. PubMed PMID: 16631505.

3. Maurovich-Horvat P, Hoffmann U, Vorpahl M, Nakano M, Virmani R, Alkadhi H. The napkin-ring sign: CT signature of high-risk coronary plaques? JACC Cardiovascular imaging. 2010 Apr;3(4):440-4. PubMed PMID: 20394906.

4. Otsuka K, Fukuda S, Tanaka A, Nakanishi K, Taguchi H, Yoshikawa J, et al. Napkin-ring sign on coronary CT angiography for the prediction of acute coronary syndrome. JACC Cardiovascular imaging. 2013 Apr;6(4):448-57. PubMed PMID: 23498679.

5. Naghavi M, Falk E, Hecht HS, Shah PK, Force ST. The first SHAPE (Screening for Heart Attack Prevention and Education) guideline. Critical pathways in cardiology. 2006 Dec;5(4):18790. PubMed PMID: 18340236.

6. Task Force M, Montalescot G, Sechtem U, Achenbach S, Andreotti F, Arden C, et al. 2013 ESC guidelines on the management of stable coronary artery disease: the Task Force on the management of stable coronary artery disease of the European Society of Cardiology. European heart journal. 2013 Oct;34(38):2949-3003. PubMed PMID: 23996286.

7. Paech DC, Weston AR. A systematic review of the clinical effectiveness of 64-slice or higher computed tomography angiography as an alternative to invasive coronary angiography in the investigation of suspected coronary artery disease. BMC cardiovascular disorders. 2011;11:32. PubMed PMID: 21679468. Pubmed Central PMCID: 3141758.

8. Abbara S, Arbab-Zadeh A, Callister TQ, Desai MY, Mamuya W, Thomson L, et al. SCCT guidelines for performance of coronary computed tomographic angiography: a report of the Society of Cardiovascular Computed Tomography Guidelines Committee. Journal of cardiovascular computed tomography. 2009 May-Jun;3(3):190-204. PubMed PMID: 19409872. 